\section{becoming animal in \\ contemporary visual arts}

NATO THOMPSON (ED)
$\begin{aligned} & \text { Becoming Animal: Contemporary Art in the } \\ & \text { Animal Kingdom }\end{aligned}$
MIT Press, Massachusetts, 2005
ISBN 0262201615
RRP US\$25 (hb)

From vivisection to the preservation of endangered species, the tangled web of both competing, and unrelated, discourses in which animals figure, largely in their relations to humans, is the concern of the growing field of 'animal studies.' Just as the 'original' and singular feminism had to come to terms with internal diversity, as have most areas of philosophical and theoretical contemplation in recent decades, in order to explain the endless numbers of specific instances of representation, the growing field of 'animal studies' is comprised of sophisticated negotiations of the complexities. The task for texts with multiple contributors in the growing 'animal studies' field is to take account of this complexity and diversity, without losing the basic level of coherence that makes reading enjoyable rather than uncontextualised or unanchored. Becoming Animal achieves this in style.

Becoming Animal is the book of the exhibition of the same name, at Massachusetts Museum of Contemporary Art, on display from May 2005 to March 2006. The book is divided by artist, thirteen in all, with two essays that come before-the first by the exhibition's curator Nato Thompson, and a slightly longer one by Christopher Cox, Associate Professor in philosophy at Hampshire College. While the two essays do share many of the same issues of discussion-as suggested by the similarity in titles: 'Monstrous Empathy' and 'Of Humans, Animals, and Monsters'-both smoothly and clearly outline the major issues and complexities of animal philosophy at this moment in time. Thompson focuses on contemporary popular cultural representations of 'monstrous' 
animality, and the work of the artists within forms of (mixed) media, which can effectively the exhibition, while Cox gives an overview of reflect issues of hybridity between animal shifting historical ideas about the relations and human.

between humanity and animality, discussing Viewed altogether, the artists make Becoming the animal aspects of 'monsters' from early Animal well-rounded not only in terms of Christian thinking to H.G. Wells' The Island of media, but of animal/human issues: there is Dr Moreau. The use of the word 'monster' by something here for everyone, as they say, from both essayists sits awkwardly in relation to the scientific categorisation and museological preexhibition, not because of Thompson and Cox's servation (Mark Dion), to extinction (Rachel specific uses of it, but more in terms of rel- Berwick, Patricia Piccinini), to artificiality and evance because, as Thompson says, the artists future biology (Piccinini, Brian Conley), to featured are generally not focused on the nega- cross-overs in animal/human experience (Sam tive and fearful aspects of human/animal con- Easterson, Kathy High), to specific political/ nections that occur throughout history and that cultural contexts (Jane Alexander). The relations preoccupy contemporary popular culture in the between women and animality, and partial and form of movies like The Fly, Species, and Alien. makeshift ways that both women and animals Thompson identifies that: 'As its conscious access in part, or negotiate, subjectivity, with its point of departure, Becoming Animal focuses inherently masculine gendering, are explored on empathetic and sympathetic approaches by Ann-Sofi Siden and Kathy High.

to hybridity rather than those conveniently A major preoccupation seen across the works fear-laden.' (9)

in Becoming Animal is that of where and how

A reader new to the area will find a solid base technology meets the 'human', in automaton/ of knowledge presented in the two essays. They machinic hybridity. As feminists have argued in provide an excellent contextualisation of the relation to understandings of the interactions of cultural and philosophical background against race, gender, and sexuality, connection between which this exhibition was conceived and pro- two axes of identity reflexively undermines duced. Thompson and Cox also give detailed other axes, or opens the way for other axes to discussion of animals in the work of particular be crossed. This chiastic operation in which the theorists, from Descartes and Rousseau to destabilising of one apparently stable category Agamben and Haraway, who provide the poten- affects other apparently stable categories is evitial for further reading in many directions. dent in a disciplinary way also, in the historical

Becoming Animal presents artists working development of animal studies. The twentieth across a broad range of media, from video instal- century's preoccupation with the binaries of lations to material ones, and from performance human/machine and man/woman has, in the art to interactive art, though no traditional past several decades, led to intensified examinpainters feature. This is probably a function of ation of the stability of other bordered catthe more inherently hybrid nature of newer egories of being, in this case that of 'human' 
and 'animal.' Quite rightly, feminists have then tial for art projects to result in superficial engageargued that human/animal negotiations should ments with the relations between humans and not allow the idea of the 'universal' (male) animals, because of their movement into 'the subject to creep back in, as an 'easier' departure- disempowering realm of the abstract'. (11) It is point for considerations of animals. Hence, the easy to imagine that an exhibition based on complexities of gender are now central to Deleuze and Guattari's 'becoming animal' connumerous investigations within the field of cept would be in danger of just this kind of animal studies. As a result of this historical superficial engagement. The complexity of the trajectory, investigations of several identity actual text of Deleuze and Guattari's 'becoming categories are frequently simultaneous: human animal' combined with its simultaneous glib and machine, machine and animal, animal quotability makes it a tricky departure point for and human, woman and human, woman and a collection.

animal. Where do the boundaries lie, then, However, I think Becoming Animal negotiates between all of these categories of being? Many brilliantly this rocky terrain of using a Big Idea of the artists in Becoming Animal-Natalie that has become dispersed through cultural Jeremijenko, Nicolas Lampert, Liz Lerman quotation, and productively breathes life into Dance Exchange, Motohiko Odani, and Michael Deleuze and Guattari's philosophy. Basically, Oatman-show, in very different ways, that the this is due to the quality of the introductory boundaries are constantly shifting, and new essays in situating the art, but most importformulations, new 'beings' are being created all antly, to the standard of the art itself. The artists the time.

here are astounding in the sheer sophistication

As the title of both the exhibition and this and depth of their considerations. In their book suggests, the anchoring theoretical, philo- works the cerebral meditations of the philossophical framework behind contemporary art ophers grow into living manifestations in which engaged with animal/human issues is Gilles these issues actually play out, in works that are Deleuze and Félix Guattari’s 'becoming-animal', moving, affecting, beautiful and very challengfrom their A Thousand Plateaus. Whether or not ing all at once.

the individual artists here are explicitly engaged The interviews with the artist that follow the with, or are aware of, Deleuze and Guattari, summary of each artist's work are instrumental it would be fair to say that the influence of in the excellence of the book, with the artists the French theorists' thought permeates arti- frequently expanding upon the theoretical culations of human/animal relations in the ideas presented in the essays, but in their own contemporary moment. As Thompson acknowl- voices, and organically, at the points at which edges in his essay, there is the potential for an such ideas motivate and explicate their work. exhibition/collection like this to miss the mark. I I read the book in one sitting, and felt comThompson quotes from Critical Art Ensemble's pelled to do so again several times subseThe Molecular Invasion (2002), about the poten- quently. Reading the whole book like this, there 
is a real sense of the range, intelligence and useful for, say, Australian academics' teaching power of these artists and their explorations. purposes.

In terms of the Australian contribution to The only-unfortunately major-problem Becoming Animal, Patricia Piccinini features, and that I experienced with Becoming Animal stares her work is discussed thoughtfully. She is one the reader in the face: design. While the written representative of a very active field of Australian words and the images in the book work artists making intensive examinations into together to inform one another, this overall human-animal relations in recent years. Lisa 'work' of the text is actively undermined by the Roet's obsession with primates has led her to production design. Inside it looks like one of produce captivating and disturbing art about those "visual guide to the space-ships in Star them for over ten years now. Roet has a strong Trek', with a pastel-pink shade 'splashed' onto international profile, but is not included in this every artist-summary page and around the exhibition. Another world-famous Australian edges of the pages with the art on them. I kept artist, Ricky Swallow, has also engaged with feeling like I'd spilt something and needed to animality and like Roet has done so specifically wipe it off. The effect of this is to distract and in relation to the film Planet of the Apes. His detract, to confuse rather than elucidate the works range from watercolour 'drawings' nuances of the project. One example of the alluding to the film, as well as his sculptures - diminishment of the issues that the book's the human-to-primate-to-The Terminator-and- design effects, is that of the 'decoration' on the back-again row of cast-resin skulls. Then there's summary page for Rachel Berwick. Her work, Ben Quilty's recent compelling paintings of the Lonesome George, features a video installation of Australian icon that is budgerigars, but with a George- the last surviving turtle of his particupostmodern twist - these budgies are 'Ameri- lar species, from the island of Pinta, north of cans', bred in the States to an American aesthetic. the Galapagos Islands. Exploring uniqueness,

Given the standards of Australian art related time, and extinction, Lonesome George is poigto animals, even though Becoming Animal is nant and sad. However, on the summary page an excellent overview for art students and that faces off against the video-still of George interested humanities scholars who want to staring into the camera, directly below the learn about contemporary artists focusing on description of Berwick's work there is a 'shadow' animal issues, for Australian readers there is the turtle- a miniaturised outline of the turtleproblem of the American bias. For a book that shape in Berwick's still—bunged in as a design challenges many other assumptions, it does not decoration. The whole point of Berwick's work challenge the nationalist assumption of Ameri- is that George is the only one left- the force of can centrality-eight of the thirteen artists are the image is defined by its singularity. American, and only two overall don't live and Another unfortunate way in which the design work in America. It's only a small point, but the undermines the content in Becoming Animal book's American-ness certainly renders it less is in the cover. Like the inside, a completely 
other genre is suggested by the cover, which is a choice of art-work that fails to give an initial impression of 'animal' art: the cover photo is from Ann-Sofi Siden's QM, I Call Her QM, otherwise an extraordinary and hauntingly intelligent performance piece/video art-work that has been ongoing for years, in which Siden performs as 'QM', a naked, mud-covered 'creature' whose wanderings into public spaces (such as when she visited the cosmetics counters of a department store) disturb viewers by throwing into relief assumptions about the boundaries of the human. However, reduced to this one shot and placed on the cover without contextualisation, it resembles a horror-movie shot, which in this context again bespeaks a confusion of genre. Combined with a title font that looks like someone went silly with gold and silver pens, the overall effect produced is that of a children's book on witchcraft. Also, I couldn't help but feel it ironic that the 'speciesism' that is the name for the centrality of the human throughout history and that this book explicitly challenges, is evident here in the insistence on a representation of a human, however 'monstrous', for the cover. Thankfully, the artists inside the book show that sustained consideration of animal/human relations is possible and rewarding. For the sake of the content, try not to judge this book by its design ... or its cover.

KATE LIVETT is completing a PhD on Gertrude Stein and fetishism in the School of English at the University of New South Wales. <klivett2@yahoo.com.au> 